\title{
Editorial
}

\section{Acesso universal em saúde e os desafios para a enfermagem brasileira em uma conjuntura de crise}

Temos percebido a retomada do uso de conceitos antigos a partir de lógicas e sentidos diferentes das quais se originaram. Os vários usos feitos pelos conceitos relacionam-se a projetos de diversas naturezas, sejam elas históricas, políticas ou institucionais. O que nos cabe enquanto categoria profissional é identificar os vários usos feitos pelos conceitos e ainda a que campos políticos-institucionais têm servido.

A saúde como direito foi proposta da Conferência Nacional de Saúde de 1986 e afirmada pela Constituição Federal Brasileira de 1988, o que implicou a construção de um projeto de saúde baseado na ideia de acesso universal.

O conceito de acesso em saúde qualifica um conjunto de interações e relações com vistas a enfrentar e dar resposta concreta aos problemas e necessidades em saúde, e se apresenta como um conceito aberto, sujeito a mudanças de acordo com os contextos históricos. Alguns autores consideram que há um deslocamento na história que faz avançar um entendimento do conceito de acesso para além de compreendê-lo apenas como oferta de serviços, incluindo também os resultados obtidos. Isto traz para o debate argumentos políticos e fatores relativos aos sujeitos que buscam os serviços, à capacidade de dar continuidade aos cuidados, e mesmo à compreensão do que é saúde. Nesse sentido, uma premissa que temos de considerar é de que não há um único projeto em jogo.

No caso do Brasil, a questão do acesso se articula às formas como as entidades e órgãos de classe da enfermagem, coletivamente, aderiram ao ideário da Reforma Sanitária, sobretudo a partir da década de 1980, quando passam a ficar mais claros os princípios que deveriam sustentar um projeto de saúde inclusivo e democrático. Com base no pensamento de sanitaristas como Sérgio Arouca, o conceito de acesso universal não se dissocia de uma compreensão política em torno do tema justiça e igualdade social. Saúde é democracia, e vice-versa, não se aceitando que o conceito ampliado de saúde se distancie da defesa intransigente da concepção de saúde como direito de toda e qualquer pessoa, e um dever do Estado, mediante políticas públicas.

$\mathrm{O}$ acesso é um dos fatores que contribui para a promoção da justiça social, e deve ser considerado no seu contexto atual, de ameaça às políticas e estruturas que configuram um estado de bem-estar, tão duramente conquistadas nas décadas de mobilização social e qualificação do Sistema Único de Saúde (SUS) como política de equidade. Nessa conjuntura, interesses diversos orientam projetos diversos. Levando-se em conta que há um esgotamento do modelo de acumulação de capital, em todo o mundo, e que o setor saúde é um dos que mais recursos financeiros consome, é preciso que todas as propostas em torno da ampliação de cobertura sejam analisadas considerando-se as dificuldades dos países, sobretudo os de capitalismo tardio como o Brasil, em garantir recursos públicos adequados, o que abre brechas para a participação do setor privado, por meio da oferta segmentada de procedimentos de saúde.

As propostas recentes de reorganização dos sistemas de saúde com base no conceito de cobertura universal de serviços vêm sendo discutidas e questionadas por entidades como o Centro Brasileiro de Estudos sobre Saúde (CEBES), a Associação Latino-Americana de Medicina Social (ALAMES) e a Associação Brasileira de Saúde Coletiva (ABRASCO), que colocam em questão o risco de simplificação de uma situação complexa, que possui determinantes macro-políticos e econômicos, pela via da oferta potencial de serviços básicos. Nesse sentido, é preciso distinguir o conceito de acesso universal do de cobertura universal, dado que esta última se refere à possibilidade de oferta generalizada de procedimentos e ações de saúde de acordo com a capacidade de pagamento das pessoas. Ou seja, apesar de falar em cobertura universal, esse tipo de modelo reduz o direito à saúde da população.

Nesse sentido, reafirmando o compromisso social da Revista Enfermagem UERJ lembramos que apenas os sistemas públicos e universais como o SUS, podem garantir saúde para todos e o direito à saúde. Parece-nos que, em tempos de crise política, institucional e no campo dos direitos sociais, o maior desafio da enfermagem brasileira seja perceber que somos a base de sustentação do SUS e, só seremos fortes se nos unirmos em torno do seu fortalecimento.

Helena Maria Scherlowski Leal David

Sonia Acioli

Editoras Associadas 